\title{
Voltammetric Quantification of Fluoxetine: Application to Quality Control and Quality Assurance Processes
}

\author{
RUI P. LENCASTRE ${ }^{\mathbf{1}}$, CRISTINA D. MATOS ${ }^{1}$, JORGE GARRIDO ${ }^{\mathbf{1}}$, \\ FERNANDA BORGES ${ }^{2}$ AND E. MANUELA GARRIDO ${ }^{1 *}$ \\ 1. Department of Chemical Engineering, School of Engineering ISEP, Polytechnic Institute of Porto, Rua S. Tomé, 4200-485 Porto, Portugal. \\ 2. Research Unit "Molecular Physical-Chemistry", Department of Organic Chemistry, Faculty of Pharmacy, \\ University of Porto, 4050-047 Porto, Portugal.
}

(Received: February 20, 2006; Accepted: June 1, 2006)

\begin{abstract}
The oxidative behaviour of fluoxetine was studied at a glassy carbon electrode in various buffer systems and at different $\mathrm{pH}$ using cyclic, differential pulse and square wave voltammetry. A new square wave voltammetric method suitable for the quality control of fluoxetine in commercial formulations has been developed using a borate $\mathrm{pH} 9$ buffer solution as supporting electrolyte. Under optimized conditions, a linear response was obtained in the range 10 to $16 \mu \mathrm{M}$ with a detection limit of $1.0 \mu \mathrm{M}$. Validation parameters such as sensitivity, precision and accuracy were evaluated. The proposed method was successfully applied to the determination of fluoxetine in pharmaceutical formulations. The results were statistically compared with those obtained by the reference high-performance liquid chromatographic method. No significant differences were found between the methods.
\end{abstract}

Key words: Fluoxetine, square wave voltammetry, oxidation, quality control, pharmaceutics.

\section{INTRODUCTION}

Depression is a significant and prevalent illness that has far-reaching effects on patients' quality of life, survival, and overall health care utilisation and needs ${ }^{(1)}$.

The class of drugs known as selective serotonin reuptake inhibitors (SSRIs), which are clinically effective for the treatment of depression, makes one of the major medicinal discoveries of the past few decades ${ }^{(2)}$. Their therapeutic usefulness is still being expanded to include new indications, such as anxiety and compulsive, post traumatic stress and pre-menstrual dysphoric disorders ${ }^{(2)}$.

Among SSRIs, fluoxetine, $( \pm)-N$-methyl-3-phenyl3 -[( $\alpha, \alpha, \alpha$-trifluoro- $p$-tolyl)oxy]propyl-amine (Figure 1 ), has become one of the most commonly prescribed antidepressant drugs worldwide and as such has received a great deal of media attention.

Fluoxetine is recommended at an initial daily dose of $20 \mathrm{mg}$. Caution is advised. A lower or less frequent dose

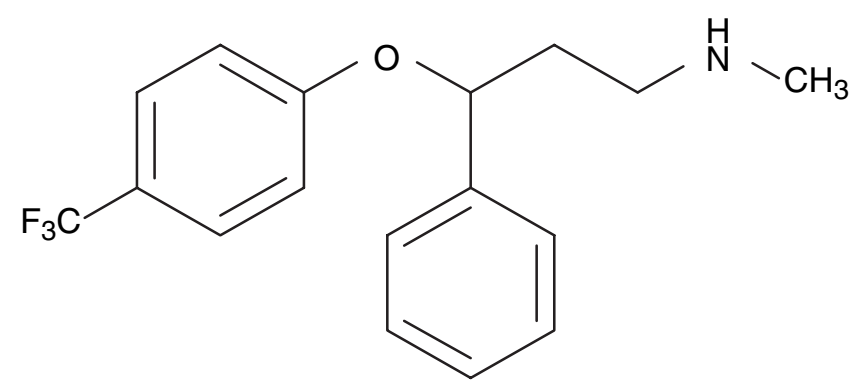

Figure 1. Structural formulae of fluoxetine.

\footnotetext{
* Author for correspondence. Tel: +351-22-8340500; Fax: +351-22-8321159; E-mail: emg@isep.ipp.pt
}

should be considered, when fluoxetine is administered to patients using multiple concomitant medications or with concurrent disease ${ }^{(3)}$.

The demand for fluoxetine analytical assay is growing with the increased use of the drug in order to monitor both compliance and unexpected toxic concentrations after a chronic use of the drug. Thus, reliable, accurate and sensitive analytical procedures are needed to determine the drug levels either in quality control or in therapeutic drug monitoring.

Several methods for fluoxetine determination have been reported in the literature. Most of these studies have determined the concentration of this compound employing gas-chromatography and high-performance liquid chromatography ${ }^{(4-6)}$. Official pharmacopoeias, such as the British Pharmacopoeia and the United States Pharmacopoeia ${ }^{(7-8)}$, report the use of liquid chromatography with UV detection for the determination of fluoxetine in formulations, capsules and oral solutions.

Spectrophotometric methods and capillary zone electrophoresis have also been used to determine fluoxetine in biological samples and pharmaceutical formulations $^{(9-12)}$.

Electrochemistry has always provided analytical techniques characterised by instrumental simplicity, moderate cost and portability. These features make electrochemical techniques particularly suitable for the determination of trace concentrations of biologically and clinically important compounds ${ }^{(13)}$. Regarding the interest and widespread use of electrochemical detectors, such as, in liquid chromatographic systems, it is intriguing that they had never been used for the analysis and detection 
of fluoxetine although the molecule structure possesses functional groups susceptible of being oxidable. In view of this, this study investigated the possibility of using electrochemical detection to analyse and quantify fluoxetine.

This work aimed to study the voltammetric behaviour and to establish the experimental conditions for the determination of fluoxetine using a glassy carbon electrode. A simple and rapid voltammetric procedure was to be developed and applied to the determination of fluoxetine in pharmaceutical dosage forms.

\section{EXPERIMENTAL}

\section{Materials and Method}

Voltammetric measurements were performed using an Autolab PGSTAT 10 potentiostat/galvanostat (EcoChimie, Netherlands) electrochemical analyser. A glassy carbon working electrode (Metrohm; diameter: 2 $\mathrm{mm}$ ), an $\mathrm{Ag} / \mathrm{AgCl}$ reference electrode (Metrohm; $3 \mathrm{M} \mathrm{KCl}$ ), a glassy carbon rod counter electrode (Metrohm) and a standard one-compartment three-electrode cell were used in all experiments. The working electrode was polished manually with aqueous slurry of alumina powder (BDH) on a microcloth pad and rinsed with water before use. All measurements were made at room temperature.

The optimum instrumental parameters to be used in the square wave voltammetric (SWV) quantification were chosen by studying the variation of the peak current $\left(I_{\mathrm{p}}\right)$ with the square wave frequency $(f)$, pulse amplitude $\left(E_{s}\right)$ and ionic strength $(I)$. The system was optimised, particularly in respect of maximum peak current and reproducibility.

The $\mathrm{pH}$ was measured using a Metrohm E-520 pHmeter and a Metrohm glass electrode.

The HPLC reference method ${ }^{(7-8)}$ was performed using a Sykam model A 1210 liquid chromatograph (Sykam, Germany), equipped with an UV detector $(\lambda=203 \mathrm{~nm})$ model 3200. Separation of sample components was accomplished at room temperature by gradient elution using a Nucleosil 120-5 C18 column $(250 \times 4.6 \mathrm{~mm}, 5 \mu \mathrm{m}$ particle size, Macherey-Nagel, Germany). The mobilephase was $20 \mathrm{mM}$ phosphate buffer $\mathrm{pH} 3.8$ - acetonitrile, at a flow rate of $1.0 \mathrm{~mL}$ per minute. The acetonitrile content of the mobile phase was increased linearly from $25 \%$ to $40 \%$ during the first $10 \mathrm{~min}$ and then to $44 \%$ in $8 \mathrm{~min}$.

\section{Chemicals}

Fluoxetine hydrochloride was provided by Merck Farma (Lisboa, Portugal). Analytical grade reagents purchased from Merck (Darmstadt, Germany) were used without additional purification. Deionised water (conductivity $<0.1 \mu \mathrm{S} \mathrm{cm} \mathrm{cm}^{-1}$ ) was used throughout the experiments. Buffer solutions employed for voltammetric determinations were $0.2 \mathrm{M}$ in the $\mathrm{pH}$ range 1.2 - 12.2.
HPLC-grade acetonitrile was obtained from Merck. Phosphate buffer $20 \mathrm{mM}$ was prepared in water and the $\mathrm{pH}$ was adjusted to 3.8 with $10 \%$ orthophosphoric acid. Prior to use, the solvents were filtered and air was removed with helium.

A standard stock solution of fluoxetine $(1 \mathrm{mM})$ was prepared in deionised water. Standard solutions were prepared in the voltammetric cell, adding accurate volumes of the stock standard solution to the selected borate $\mathrm{pH} 9$ supporting electrolyte in order to obtain concentrations between 10 and $16 \mu \mathrm{M}$. The calibration curve for SWV analysis was constructed by plotting the peak current against the fluoxetine concentration (10.0, 11.5, 13.0, 14.5 and $16.0 \mu \mathrm{M}$ ). The limit of quantification (LOQ) and the limit of detection (LOD) were calculated according to USP guidelines ${ }^{(8)}$. A S/N ratio of ten and three was used respectively. Method precision was checked at different days, within day $(n=5)$ and between days $(n=5)$ for three different concentrations. The accuracy of the proposed method was determined by comparing the results obtained with those from reference methods ${ }^{(7-8)}$.

\section{Pharmacentical Dosage form Assay Procedure}

Fluoxetine content was determined in commercial formulations available in Portugal; each capsule contains $20 \mathrm{mg}$ of fluoxetine and the oral solution holds $20 \mathrm{mg}$ per $5 \mathrm{~mL}$ of fluoxetine.

The average mass of ten capsules was determined. The capsule contents were emptied as completely as possible. An adequate amount of this powder equivalent to $1 \mathrm{mM}$ was weighed and dissolved with deionised water. The solution was filtered to remove any remaining insoluble matter. Working solutions of the pharmaceutical formulations were prepared exactly as the standard solutions. A suitable volume of oral solution was just diluted with water to achieve the appropriate concentration.

\section{RESULTS AND DISCUSSION}

As no electrochemical data was available concerning its oxidative behaviour, the electrochemical oxidation of fluoxetine was studied in a broad $\mathrm{pH}$ range $(1.2-12.2)$ using a glassy carbon electrode. The differential pulse voltammetric (DPV) behaviour of fluoxetine yielded one anodic wave starting at $\mathrm{pH} 6$ (Figure 2). As the $\mathrm{pH}$ increase, a second poorly resolved wave appears at $\mathrm{pH} 8$ (Figure 2). The peak potential $\left(E_{\mathrm{p}}\right)$ of the oxidation process moved to less positive potential by raising the $\mathrm{pH}$ (Figure 3). The influence of $\mathrm{pH}$ on the fluoxetine peak current at a glassy carbon electrode was also studied. The $I_{\mathrm{p}}$ versus $\mathrm{pH}$ plot shows that peak current reaches a maximum value at $\mathrm{pH} 9$ (Figure 3). The experimental results showed that shapes of the curves were better defined in borate buffer pH 9 than in ammonia or Britton-Robinson buffers. Hence, this electrolyte was used throughout this study. 
The cyclic voltammetric behaviour of fluoxetine at $\mathrm{pH} 9$ presented one well-defined wave at $E_{\mathrm{p}}=+0.90 \mathrm{~V}$. Cyclic voltammetric measurements showed an irreversible nature of the oxidation process, since no reduction wave was observed on the cathodic branch. It was also observed that at the second and higher cycles the fluoxetine current intensity decreased. This occurrence could be attributed to the adsorption of the oxidation products on the electrode surface. Scan rate studies were carried out to assess whether the oxidation process at the glassy carbon electrode was under diffusion or adsorption control. The scan rate (v) varied from 10 to $1000 \mathrm{mV} \mathrm{s}^{-1}$ in $100 \mu \mathrm{M}$ solution of fluoxetine. From the dependence of peak current on sweep rate, it is possible to conclude that the process is diffusion controlled between 10 and $250 \mathrm{mV} \mathrm{s}^{-1}$. A plot of $\mathrm{d} \log I_{\mathrm{p}}$ $/ \mathrm{d} \log v$ over this scan range gave a straight line with a slope of 0.58 , which also indicates a diffusion-controlled

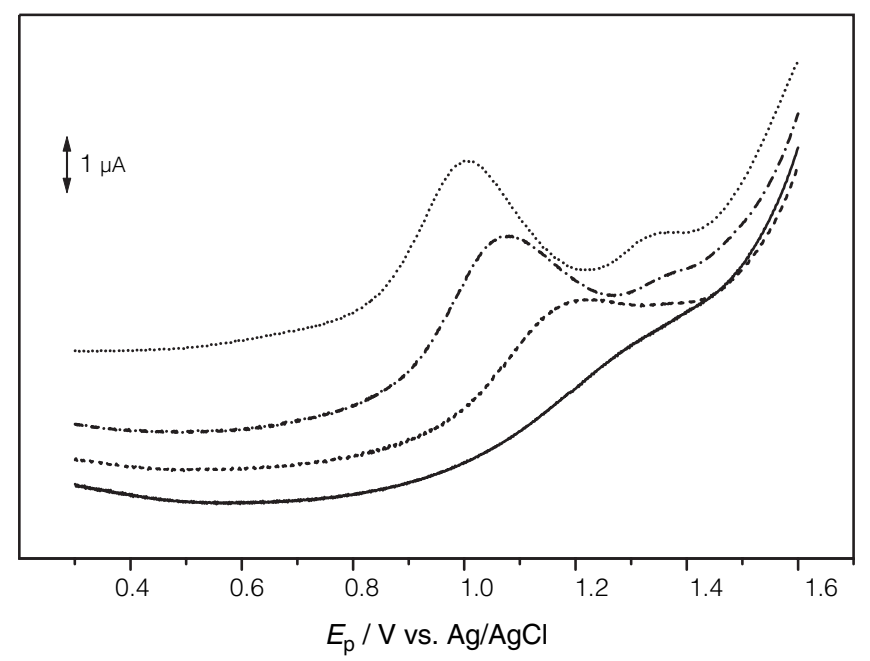

Figure 2. Differential pulse voltammograms of a $100 \mu \mathrm{M}$ solutions of fluoxetine in (-) pH 6 phosphate buffer, (---) pH 7 phosphate buffer, (--.-) pH 8 phosphate buffer and (…) pH 9 borate buffer. Scan rate $5 \mathrm{mV} \mathrm{s}^{-1}$.

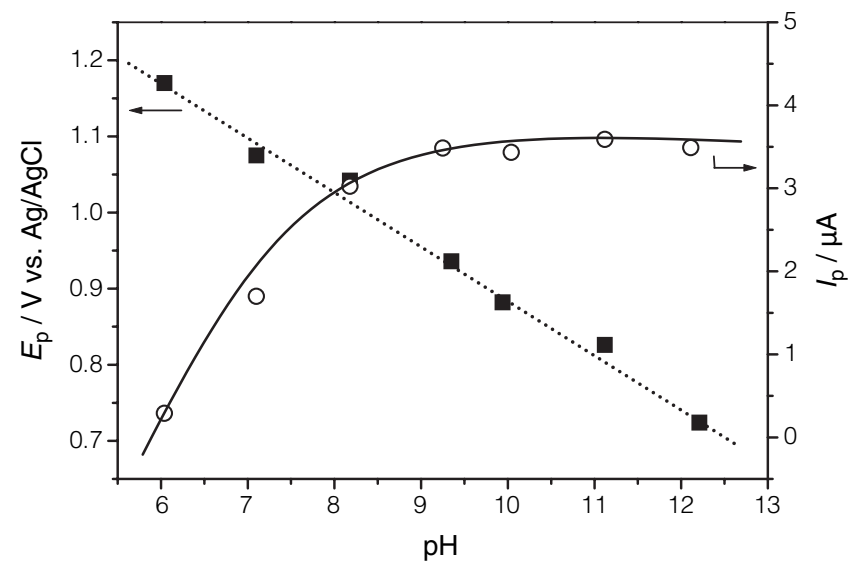

Figure 3. Plots of $E_{\mathrm{p}}$ (filled symbols) and $I_{\mathrm{p}}$ (open symbols) vs. $\mathrm{pH}$ from differential pulse voltammograms of $100 \mu \mathrm{M}$ solutions of fluoxetine in $0.2 \mathrm{M}$ ionic strength buffer electrolyte. Scan rate $5 \mathrm{mV} \mathrm{s}^{-1}$. process $^{(14)}$. The peak potential was shifted to more positive values on increasing the scan rate, which also confirms the irreversible nature of the oxidation process.

In order to prevent adsorption of fluoxetine and/or its oxidation products on the electrode surface, a study on the effect of the addition of different percentages of the surfactant, Tween 20, was carried out. The use of low percentages of the surfactant did not eliminated completely the adsorption effects observed for high concentrations of fluoxetine. On the contrary, at high percentages adsorption of the surfactant itself on the electrode surface led to a diminution of the peak current, despite the greater reproducibility obtained. The best results were obtained for the addition of $0.5 \%$ of Tween 20 to the solution.

\section{Analytical Application of the Proposed Method}

A quantitative analytical method was developed based on the voltammetric study of fluoxetine. The best ratio of the peak to background currents was obtained

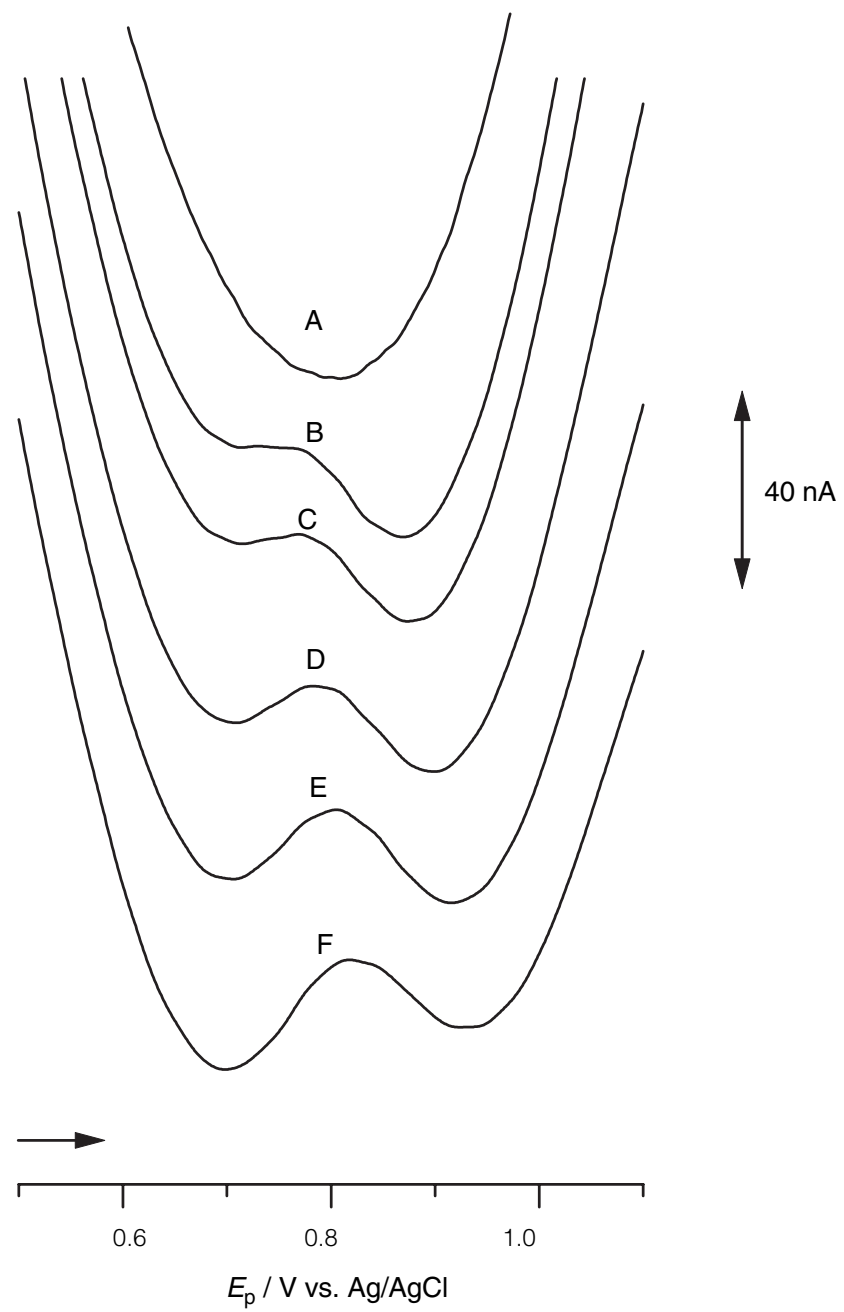

Figure 4. Successive square wave voltammograms, in $\mathrm{pH} 9$ borate buffer electrolyte, of standard solutions of fluoxetine: A - 0.0, B 10.0, C - 11.5, D - 13.0, E - 14.5 and $\mathrm{F}-16.0 \mu \mathrm{M}$. Frequency 200 $\mathrm{Hz}$; pulse amplitude $50 \mathrm{mV}$. 
using square wave voltammetry. This technique had also originated sharper and better defined peaks resulting in improved resolution. Optimisation of the SWV parameters regarding peak definition and current was accomplished using $f=200 \mathrm{~Hz}, E_{S}=50 \mathrm{mV}$ and $I=0.2 \mathrm{M}$ (see Experimental section).

Square wave voltammograms recorded with increasing amounts of fluoxetine showed that the peak current increased linearly with increasing concentration (Figure 4). A linear relation between peak current and fluoxetine concentration was observed in the range 10 to $16 \mu \mathrm{M}$. The characteristics of the calibration plots are summarized in Table 1. The limit of detection (LOD) and the limit of quantification (LOQ), calculated according to USP guidelines [8], were 1.0 and $7.1 \mu \mathrm{M}$, respectively.

The precision of the method was evaluated at three levels of concentration $(10,13$ and $16 \mu \mathrm{M}$ ) (results shown in Table 1). Specificity of the optimized procedure for the assay of fluoxetine was examined through recovery trials, in the presence of excipients (e.g. starch, lactose, sucrose) at concentrations that can be found in the formulations. The results indicated the absence of significant interference from any of the excipients found in the pharmaceutical formulations tested. On the basis of these results, the proposed method was applied to the determination of fluoxetine in commercial capsules and oral solutions. To evaluate the accuracy of the proposed technique, the results were compared with those obtained by the reference method ${ }^{(8)}$ (Table 2).

The $F$ - and Student $t$-test were carried out on the data and statistically examined the validity of the obtained results (Table 2). At the 95\% confidence level, the values of $t$ - and $F$-tests were less than the theoretical values

Table 1. Linearity range, quantification and detection limits and intra- and inter-day repeatability for determination of fluoxetine using the square wave voltammetric method (SWV).

\begin{tabular}{lc}
\hline & SWV \\
\hline Linearity range $(\mu \mathrm{M})$ & $10-16$ \\
Calibration graph $(n=5)$ & \\
Intercept $(\mu \mathrm{A})$ & 0.023 \\
Slope $\left(\mathrm{mA} \mu \mathrm{M}^{-1}\right)$ & 2.84 \\
Correlation coefficient & 0.995 \\
Standard error of intercept & 0.03 \\
Standard error of slope & 0.06 \\
Intra-day precision $(\mathrm{n}=5)^{\mathrm{a}}$ & \\
$\quad 10 \mu \mathrm{M}$ & 2.3 \\
$\quad 13 \mu \mathrm{M}$ & 1.6 \\
$\quad 16 \mu \mathrm{M}$ & 1.8 \\
Inter-day precision $(\mathrm{n}=5)^{\mathrm{a}}$ & \\
$10 \mu \mathrm{M}$ & 3.0 \\
$13 \mu \mathrm{M}$ & 2.1 \\
$16 \mu \mathrm{M}$ & 1.8 \\
LOD $(\mu \mathrm{M})$ & 1.0 \\
LOQ $(\mu \mathrm{M})$ & 7.1
\end{tabular}

${ }^{\text {a Precision as coefficient of variation }(\mathrm{CV}, \%)=\text { standard deviation }}$ divided by mean measured concentration $\times 100$. showing that there are no significant differences between the proposed and reference methods.

\section{CONCLUSIONS}

This study has shown that fluoxetine can be determined by using the square wave voltammetric technique on the basis of its oxidation process at a glassy carbon electrode. The method has been successfully applied to the direct determination of fluoxetine, without complex pre-treatment of the samples other than dissolution or dilution, in pharmaceutical formulations with adequate reproducibility and sensitivity.

The reported technique constitutes an alternative method that can be implemented for routine analysis of fluoxetine in pharmaceutical formulations. Moreover, the results obtained outlook the possibility of development of a successful HPLC strategy based on electrochemical detection that is ideal for therapeutic drug monitoring purposes and to study the metabolism of the drug, which could enable the simultaneous determination of fluoxetine and its metabolites in biological matrixes.

\section{ACKNOWLEDGEMENTS}

We express our gratitude to Paula Paíga for helping with HPLC determinations. The authors also gratefully acknowledge Merck Farma (Lisboa, Portugal) for supplying standard fluoxetine sample.

Table 2. Application of the square wave voltammetric method (SWV) to the determination of fluoxetine in commercial pharmaceutical preparations.

\begin{tabular}{|c|c|c|}
\hline Formulation & $\mathrm{SWV}^{\mathrm{a}}$ & Reference method (HPLC) ${ }^{\mathrm{a}}$ \\
\hline Fluoxetine Irex ${ }^{\circledR}$ & $19.6 \pm 0.4$ & \\
\hline$t^{\mathrm{b}}$ & 1.4 & $20.2 \pm 0.5$ \\
\hline$F^{\mathrm{c}}$ & 1.6 & \\
\hline Fluoxetine Merck ${ }^{\circledR}$ & $20.2 \pm 0.9$ & \\
\hline$t^{\mathrm{b}}$ & 0.7 & $19.8 \pm 0.9$ \\
\hline$F^{\mathrm{c}}$ & 1.0 & \\
\hline $\operatorname{Psipax}^{\circledR}$ & $19.9 \pm 0.9$ & \\
\hline$t^{\mathrm{b}}$ & 0.4 & $19.7 \pm 0.6$ \\
\hline$F^{\mathrm{c}}$ & 2.2 & \\
\hline Nodepe ${ }^{\circledR}$ & $20.1 \pm 0.9$ & \\
\hline$t^{\mathrm{b}}$ & 1.2 & $19.4 \pm 0.9$ \\
\hline$F^{\mathrm{c}}$ & 1.0 & \\
\hline Prozac ${ }^{\circledR}$ & $20.5 \pm 0.8$ & \\
\hline$t^{\mathrm{b}}$ & 0.3 & $20.7 \pm 0.9$ \\
\hline$F^{\mathrm{c}}$ & 1.3 & \\
\hline
\end{tabular}




\section{REFERENCES}

1. Panzarino, P.J. and Nash, D.B. 2001. Cost effective treatment of depression with selective serotonin reuptake inhibitors. Am. J. Manag. Care 7: 173-184.

2. Spinks, D.and Spinks G. 2002. Serotonin reuptake inhibition: an update on current research strategies. Curr. Med. Chem. 9: 799-810.

3. Cheer, S.M. and Goa, K.L. 2001. Fluoxetine. A review of its therapeutic potential in the treatment of depression associated with physical illness. Drugs 61: 81-110.

4. Eap, C.B. and Baumann, P. 1996. Analytical methods for the quantitative determination of selective serotonin reuptake inhibitors for therapeutic drug monitoring purposes in patients. J. Chromatogr. B 686: 51-63.

5. Nevado, J.J.B., Llerena, M.J.V., Salcedo, A.M.C. and Nuevo E.A. 2000. Determination of fluoxetine, fluvoxamine and clomipramine in pharmaceutical formulations by capillary gas chromatography. J. Chromatogr. Sci. 38: 200-206.

6. El-dawy, M.A., Mabrouk, M.M and El-Barbary F.A. 2002. Liquid chromatographic determination of fluoxetine. J. Pharm. Biomed. Anal. 30: 561-571.

7. British Pharmacopoeia, The Stationery Office, London, 2005, pp. 2487-2488.

8. U.S. Pharmacopeia, 28th ed., United States Pharmacopeial Convention, Rockville, 2005, pp. 853-856.
9. Prabhakar, A., Patel, V.B. and Giridhar R. 1999. Spectrophotometric determination of fluoxetine hydrochloride in bulk and in pharmaceutical formulations. J. Pharm. Biomed. Anal. 20: 427-432.

10. Desiderio, C., Rudaz, S., Raggi, M.A. and Fanali S. 1999. Enantiomeric separation of fluoxetine and norfluoxetine in plasma and serum samples with high detection sensitivity capillary electrophoresis. Electrophoresis 20: 3432-3438.

11. Khan, I.U., Aman, T., Iqbal, M.A. and Kazi A.A. 2000. Spectrophotometric quantitation of fluoxetine hydrochloride using benzoyl and potassium iodide. Mikrochim. Acta 134: 27-31.

12. Flores, J.R., Nevado, J.J.B., Salcedo, A.M.C. and Díaz M.P.C. 2004. Development of a capillary zone electrophoretic method to determine six antidepressants in their pharmaceutical preparations. Experimental design for evaluating the ruggedness of method. J. Sep. Sci. 27: 33-40.

13. Viré, J.C., Kauffmann, J.M. and Patriarche, G.J. 1988. Electrochemical Detection Techniques in the Applied Biosciences. Junter, G.A. ed. Ellis Horwood Limited, Chichester, England.

14. Gosser, D.K. 1993. Cyclic Voltammetry. Simulation and Analysis of Reaction Mechanisms. pp. 27-70.VCH, New York, U.S.A. 